dwelling counterparts. So technology that builds the boats leads directly to biological adaptation and evolution.

To talk of 'self-made man' in this way is perhaps misleading if it refers to any unique evolutionary mechanisms relating to technology, as Kingdon seems to suggest. All evolutionary change is essentially the result of a tight feedback between the behaviour of the organism and the environments in which it finds itself. What is unique about humans is the rate at which this has occurred and the consequences for other species.

Kingdon's ideas may seem like a recipe for environmental determinism, but the link drawn between a recent origin for humans and the fundamentally local nature of adaptation means that his book is also a powerful indictment of any attempt to rank human populations in terms of progress or to see the evolution of human races as anything other than short-term responses to particular problems. Human diversity is the product of this process endlessly repeated and re-sorted over tens of thousands of years. So the classic typological races disappear in the scientific reality of time, environment and geography.

Books on human evolution are often written by those who are not specialists in the subject and the results can be catastrophic or embarrassing. But Kingdon's knowledge of the diversity of African animal life and environments enables him to cast a light on human evolution that many specialists would do well to consider seriously (despite reservations about details) and that many others will simply enjoy.

Robert Foley is in the Department of Biological Anthropology, University of Cambridge, Downing Street, Cambridge CB2 3DZ, UK.

\title{
What the British do best
}

\section{Kevin Burke}

\section{Encyclopedia of the Solid Earth Sciences. Editor-in-chief Philip Kearey. Blackwell Scientific: 1993. Pp. 713. £99.50, \$179.95.}

THIS is a good book. It is comprehensive and technical enough to meet the needs of professionals and is easy to use.

New to me is the mixing of three styles of article: short definitions, 200-word entries and extended essays of up to 1,500 words. There are 2,700 entries, but the editors emphasize the importance of their alphabetical index with three times as many terms covering key words from the articles and synonyms. The intention is that indexing and cross-referencing should ease the pursuit of a topic in depth. I pursued 'perovskite'. The primary entry was a compositional definition, but two of seven further entries did take me to the deep mantle. There is no text entry for 'dinosaur', but the index gives 11 references that together cover these creatures thoroughly, although some reveal the British distaste for an impact as the cause of the Cretaceous/Tertiary extinction.

Nearly all the 65 contributors work in the United Kingdom, a bias that has slightly influenced the selection of topics and viewpoints. I do not think that "valley bulging" would have had an entry in a similar work from any other country. British strengths emerge. Structural geology is covered well and, among applied topics, so too is engineering geology. Mention of global change is hard to discern, but there is an excellent essay on the history of the Earth sci- ences. References to books and articles are an asset. Entries are initialled so that it is usually clear who wrote what. Some articles, however, are misleading: for instance, in several places it is indicated that continental material has not been recycled into the mantle.

The illustrations, drawn specially or adapted, are large, clearly labelled and handsome. The conodont animal looks at ease swimming alongside a collection of her teeth, but the accompanying article does not refer to the identification of dentine as a strong indicator of vertebrate affinity. The few photographs are uneven. A Landsat image of Tibet is magnificent but the cliffs of Moher are as black as the O'Loughlins who ruled them. And the many short definitions for minerals seem out of place in an encyclopaedia (I prefer my American Geological Institute glossary, in which I can find 'burkeite').

Some hyperbole on the dust jacket says that the volume is "essential for professional earth scientists". I would not go so far, but this is a good place to start finding out about unfamiliar topics. Students with limited time to complete an essay would do well to begin here, although they are likely to get a British perspective and, inevitably, some less than comprehensive coverage. As a final thought, my enjoyment of the longer essays made me regret that we still do not have an Oxford Companion to the Earth Sciences.

Kevin Burke is in the Department of Geosciences, University of Houston, Houston, Texas 77204-5503, USA.

\section{Untangling data and theory}

\section{Deborah M. Gordon}

Spiders in Ecological Webs. By D. H. Wise. Cambridge University Press: 1993. Pp. 328. £45, \$79.95.

COMMUNITY ecology is struggling to bring data and theory together. Is it possible to establish any general principles of ecology? Do we need more data or better theory? This book contributes to the debate by looking at existing data on spiders. Wise considers some basic problems of community ecology: how important competition is; whether niche partitioning structures communities; how much can be explained by food webs; and how to determine the effects of one population on the dynamics of another. His discussion is based mainly on the results of field experiments, and he concludes that spiders are limited in numbers by food supplies, yet do not compete with each other for food or limit the population sizes of their prey. The tone of the book is upbeat, with the author arguing that more data of the right sort will resolve the outstanding questions of community ecology.

The empirical literature is carefully reviewed, with an emphasis on the evaluation of field methods, data analysis and experimental design. At least to someone outside the field of spider ecology, Wise's discussion of his colleagues' work seems fair and even-handed. The writing is straightforward and generally very accessible, although it is sometimes prone to metaphorical entanglements in discussions of the big picture. Spider lovers will enjoy an amazing abundance of spiderly puns; the title is only the beginning.

The book will be useful reading for anyone seeking to bridge the gap between data and theory in ecology. It should make an interesting text for a graduate-level course in community ecology, help students to plan research and set any ecologist thinking about possible generalizations.

Deborah M. Gordon is in the Department of Biological Sciences, Stanford University, Stanford, California 94305-5020. USA.

\section{New Journals issue}

This year. Nature's annual New Journals review supplement will appear in the issue of 7 October. Publishers and learned societies are invited to submit journals for review. For further information please see last week s issue or telephone Peter Tallack on 071 836-6633 (011-44-71-836-6633 from the United States), extension 2414 